\title{
Heterogeneous Preferences for Oysters: Evidence from Field Experiments
}

\section{Tongzhe Li, Maik Kecinski, and Kent D. Messer*}

\begin{abstract}
This study uses field experiments to investigate consumer preferences for oysters. In total, 486 adult participants completed a series of revealed-preference dichotomous-choice tasks and a demographic survey. Using a random effects logit model, we investigate factors that influence participants' decisions to purchase oysters. As expected, price had a significant negative effect, while income had a positive effect. Older individuals and those who were relatively selective regarding shell color or smell are less likely to buy oysters, but consumers who valued size, oyster species, and harvest location were willing to pay more.
\end{abstract}

Key Words: consumer preferences, field experiments, oyster attributes, willingness to pay

In 2014, the United States produced 9.5 billion pounds of oysters valued at $\$ 5.5$ billion (National Oceanic and Atmospheric Administration (NOAA), 2016a). Oyster aquaculture is an increasingly large component of total production and was valued at $\$ 1.2$ billion annually in 2014 in the United States alone. In the same year, the annual world aquaculture production was worth almost $\$ 100$ billion (NOAA, 2016b). Oysters are more than just a nutritious food product; they are also a public good that provides ecosystem services. In fact, NOAA supports using shellfish aquaculture as a nutrient management

Tongzhe Li: Department of Economics, University of Windsor, 401 Sunset Avenue, Windsor, Ontario N9B 3P4, Canada. Email: tongzhe@uwindsor.ca. Maik Kecinski: Department of Resource Economics and Environmental Sociology, University of Alberta, 505 General Services Building, Edmonton, AB T6G2H1. Email: kecinski@ualberta.ca. ${ }^{*}$ Correspondence: Kent D. Messer: Department of Applied Economics and Statistics " University of Delaware " 531 S. College Ave " Newark, Delaware 17616 - phone: 302-831-1316 -Email: messer@udel.edu.

The authors gratefully acknowledge funding from the United States Oceanic and Atmospheric Administration grant NA140AR4170087, State of Delaware Federal Research and Development Matching Grant Program grant 16A00407, USDA-ERS funded CBEAR (award 59-6000-4-0064), NSF EPSCoR Rii3 1301765, and USDA HATCH. Note that this is one of multiple experimental studies that are conducted under the aforementioned funding sources. We would like to thank Sunny Jardine, George Parsons, John Ewart, Edward Lewandowski, Doris Hicks, two anonymous referees and the editor for their helpful comments. We would also like to thank Daniel Awokuse, George Esterling, Julia Parker, Francesca Piccone, Kaitlynn Ritchie, Maddi Valinski, Shang $\mathrm{Wu}$, and Huidong $\mathrm{Xu}$ for research assistance.

The views expressed are the authors' and do not necessarily represent the policies or views of any sponsoring agencies.

Agricultural and Resource Economics Review 46/2 (August 2017) 296-314

(C) The Author(s) 2017. This is an Open Access article, distributed under the terms of the Creative

Commons Attribution licence (http://creativecommons.org/licenses/by/4.0/), which permits unrestricted re-use, distribution, and reproduction in any medium, provided the original work is 
practice to improve water quality and has established a restoration center to increase oyster population (NOAA, 2016c). However, rapid growth in aquaculture is challenging for the oyster industry in terms of economic returns because consumer demand needs to keep up with rapidly expanding production (Anderson, 1995; Gempesaw et al., 1995). Recently, numerous studies have emphasized the value of oysters, both as a nutritious food and as a provider of ecosystem services through water filtration (e.g., Liu et al., 2006; Loose, Peschel, and Grebitus, 2013; Rose, Bricker, and Ferreira, 2015; Kecinski, Messer, and Peo, 2016; Kecinski et al., 2017).

When addressing demand, it is important to understand what drives consumers' purchasing behaviors and how to identify potential consumers. For example, in Delaware, which is the only coastal US state that currently lacks a commercial aquaculture industry, policymakers and potential oyster farmers are keenly interested in consumer preferences for various types of oysters and oyster products. A few studies have examined oysters in terms of market reactions to food processing and food safety labeling (Bruner et al., 2014; Dedah, Keithly, and Kazmierczak., 2011), but little is known about consumer preferences for oysters compared to other seafood products (Manalo and Gempesaw, 1997).

In this research, we use incentive-compatible economic field experiments to analyze the heterogeneity of participants' preferences for a variety of oyster attributes. Using econometric analysis, we draw conclusions about potential demand and consumer preferences that allow us to infer policy-relevant implications for the growing market for oyster aquaculture. Specifically, our study contributes to the literature on oyster production and marketing by investigating four primary research questions: (1) What demographic characteristics are associated with higher (or lower) willingness to pay (WTP) for oysters? (2) Which preparations do consumers prefer? (3) Which oyster attributes do consumers value most, and which appear to be unimportant? (4) What factors contribute to heterogeneity in consumer preferences for oysters?

\section{Experiment Design}

Field experiments were conducted at four locations in Delaware: the State Division of Motor Vehicles, a local brewery, a tavern, and an annual community event. ${ }^{1}$ The administrators recruited respondents randomly at each location. ${ }^{2}$

\footnotetext{
1 The specific location effect on consumer WTP was found to be insignificant for any location. In addition, including these site-specific variables did not significantly change the estimation coefficient or significance level of other variables.

2 The data from these field experiments were collected as part of a larger project on various aspects of consumer demand for oysters.
} 
We used a price-based revealed-preference model to estimate consumer WTP for oysters. In a single-bounded dichotomous-choice format, participants were offered an opportunity to purchase and consume oysters. Those who chose to purchase oysters completed the following choice tasks sequentially: the number of oysters to purchase, preparation of the oysters, and WTP for oysters at various prices. Participants could buy three, six, nine, or twelve oysters, and the oysters could be prepared raw on a half shell, deep fried, or taken home in a bag on ice. After selecting the number of oysters to buy and the style of preparation, participants answered eight dichotomous-choice questions regarding purchasing oysters at randomly generated prices. The posted prices were obtained from random draws from a normal distribution that was based on a set of typical market prices for oysters, $\mathrm{p} \sim \mathrm{N}\left(1.5,0.5^{2}\right)$, resulting in a common range between $\$ 0.5$ to $\$ 2.5$ per oyster. The price distribution was based on consultations with local oyster experts and represents the common market prices for oysters at the time.

Prior to these experiments, we gathered information from local oyster experts, such as restaurant owners, retailers, fishermen and conservation professions to identify a number of oyster characteristics (options) that would accurately reflect important real-world questions to be included in this research. In total, eight different oyster options were offered in the experiment, which comprise the eight dichotomous choice decisions participants made in the experiments. Specifically, these options incorporate the locations from where the oysters were harvested: (1) local, (2) nonlocal, (3) east coast, and (4) west coast; and the nutrients present in the water column: (5) high, (6) medium, (7) low, and (8) unknown. A typical dichotomous choice question in the experiments would then ask participants if the wanted to purchase an oyster with those treatment characteristics for a given price. This price was determined prior to the experiment and shown to the participant along with the treatment information. For example, a participant could be asked if they would purchase local oysters for $\$ 1.75$ each. To account for potential order effects, the order of presentation for each oyster product that carries different characteristics was randomized before participants made their purchasing decisions.

The oysters offered in the experiment varied by the level of nutrients in the water from which the oysters were harvested as determined by NOAA's National Estuarine Eutrophication Assessment Update (Bricker et al., 2007). Participants responded to each oyster option and listed price by selecting "yes" or "no." To maintain incentive-compatibility, one of the eight decision rounds was randomly selected for implementation at the end of the experiment. In this setting, the participant's dominant strategy is to answer "yes" and purchase oysters only if the listed price is lower than the participant's true WTP. The experiment took approximately ten minutes, and each participant received a $\$ 10$ participation fee.

All individuals who participated in the experiment completed a survey that collected information on their demographic characteristics, shopping 
behaviors, and perceptions regarding a number of oyster attributes. The survey was developed in collaboration with local seafood extension personnel and other experts from the seafood industry, including restaurant owners, policymakers, and aquaculture experts. We chose eight oyster attributes for the survey - appearance, species, size, saltiness, smell, shell color, meat color, and harvest location - based on discussions with those experts.

The same set-up, signs, and recruitment dialogues were adopted consistently at each location throughout the study. With the assistance of banners and flyers, administrators randomly approached individuals at each location and verbally recruited adult participants. After participants indicated that they were oyster consumers and expressed an interest in taking part in the study, a consent form was provided to them. Once they read and signed the consent form, they were handed a tablet computer containing the eight experiment questions and the survey.

All of the experiments and surveys were performed on Microsoft Surface Pro computers running Willow, a Python-based software library for experimental economics. The dichotomous-choice questions presented to participants were randomized to avoid potential order effects. After completing the experiment and the survey, participants who had chosen to purchase the oysters in the decision selected for implementation paid the posted price from the $\$ 10$ participation fee and were given the oysters. Participants who did not buy oysters in the implemented round received the full participation fee and no oysters.

In each experiment, one or two employees of a professional oyster-shucking service brought equipment to the site and prepared and presented the oysters, ensuring both high-quality presentations and adherence to food safety requirements. The participants made their decisions in a space that was physically separate from the shucking table. Thus, the participants could not see, smell, or taste the exact oysters they were considering for purchase.

\section{Econometric Model}

We use a single-bounded dichotomous-choice model to evaluate the outcomes of the field experiments (Venkatachalam, 2004). The use of dichotomous-choice models has been shown to avoid a downward estimate of WTP that has been observed with some auction formats (Wu et al., 2014). The eight dichotomous-choice questions each generate two possible outcomes in single-bounded models: a respondent is or is not willing to purchase oysters at the posted price. The choice model with two potential outcomes allows us to place the respondent's true WTP for oysters in one of two intervals, $(-\infty, p)$ or $[p,+\infty)$, where $p$ is the listed price randomly drawn from market prices for oysters. The bidding mechanism results in the following discrete outcomes: 


$$
D=\left\{\begin{array}{lll}
0 & W T P<p & (\mathrm{No}) \\
1 & p \leq W T P & \text { (Yes) }
\end{array}\right.
$$

Each individual WTP outcome is based on a random utility model in which the respondent maximizes utility by choosing to purchase a product at the associated price if the utility derived from the good is greater than the utility derived from refusing the price and foregoing the product. The probability of each outcome can be expressed as

$$
\operatorname{Pr}(Y=D)=\left\{\begin{array}{c}
F(v(p, \mathbf{Z})) \\
1-F(v(p, \mathbf{Z}))
\end{array}\right\} \text { for } D=\left\{\begin{array}{l}
0 \\
1
\end{array}\right\}
$$

$F(\cdot)$ is a cumulative distribution function that characterizes the random components of utility, $v(p, \mathbf{Z})$ is the difference in indirect utility between purchasing the product at price $p$ and declining the price, and $\mathbf{Z}$ is a vector of characteristics that influence indirect utility. The function $v(p, \mathbf{Z})$ in equation (2) for individual $i$ can be written as

$$
\begin{aligned}
& v\left(p_{i j}, \mathbf{Z}_{i j}\right)=\alpha-\rho^{\prime} p_{i j}+\lambda^{\prime} \mathbf{X}_{i}, \\
& \quad i=1,2, \ldots, n \quad j=1,2, \ldots, 8
\end{aligned}
$$

where $p_{i j}$ is the price of oyster $j$ offered to respondent $i$, and $\mathbf{X}_{i}$ is a vector of observable characteristics of respondent $i$. $\mathbf{X}_{i}$ consists of the frequency of a participant consuming oysters per year, gender, age, education, income, shopping behavior, and oyster perception factors calculated using factor analysis. $\alpha, \rho$, and $\lambda$ are unknown parameters to be estimated. Then, the loglikelihood function can be expressed as

$$
\ln L=\sum_{i=1}^{n}\left\{\begin{array}{l}
I_{D=0} \ln F\left(\alpha-\rho^{\prime} p_{i j}+\lambda^{\prime} \mathbf{X}_{i}\right)+ \\
I_{D=1} \ln \left[1-F\left(\alpha-\rho^{\prime} p_{i j}+\lambda^{\prime} \mathbf{X}_{i}\right)\right]
\end{array}\right\}
$$

where $I_{D=\{0,1\}}$ represents the indicators for each $D$ outcome for individual $i$. We define $F(\cdot)$ as the standard logistic distribution with mean zero, a within-subject error term $\mu_{i} \sim N\left(0, \sigma_{\mu}^{2}\right)$, and an individual error term $\varepsilon_{i j} \sim N\left(0, \sigma^{2}\right)$ where $\sigma^{2}=$ $\left((\pi / \sqrt{3})^{2}\right)$.

\section{Results}

Collectively for the four experiment locations, 486 adults participated in the dichotomous-choice experiment and survey. Their demographic characteristics are summarized in Table 1: 51 percent were female, 70 were 
Table 1. Summary Statistics for Demographic Variables

\begin{tabular}{|c|c|}
\hline Number of respondents & 486 \\
\hline Average age (years) & 37 \\
\hline Variable & Percentage of Respondents \\
\hline Female & $51.44 \%$ \\
\hline Primary shopper & $70.12 \%$ \\
\hline \multicolumn{2}{|l|}{ Education (highest level) } \\
\hline Some school & $2.68 \%$ \\
\hline High school diploma & $17.95 \%$ \\
\hline Some college & $37.45 \%$ \\
\hline Bachelor's degree & $24.07 \%$ \\
\hline Advanced degree or graduate degree & $16.05 \%$ \\
\hline \multicolumn{2}{|l|}{ Household Income (in 2014 or 2015) } \\
\hline Less than $\$ 10,000$ & $12.60 \%$ \\
\hline$\$ 10,000$ to $\$ 24,999$ & $12.60 \%$ \\
\hline$\$ 25,000$ to $\$ 34,999$ & $11.97 \%$ \\
\hline$\$ 35,000$ to $\$ 74,999$ & $23.32 \%$ \\
\hline$\$ 75,000$ to $\$ 99,999$ & $11.97 \%$ \\
\hline$\$ 100,000$ to $\$ 149,999$ & $15.76 \%$ \\
\hline$\$ 150,000$ to $\$ 249,999$ & $8.61 \%$ \\
\hline$\$ 250,000$ or more & $3.15 \%$ \\
\hline \multicolumn{2}{|l|}{ Political Affiliation } \\
\hline Conservative & $26.47 \%$ \\
\hline Moderate & $33.61 \%$ \\
\hline Liberal & $34.24 \%$ \\
\hline Other & $5.67 \%$ \\
\hline \multicolumn{2}{|l|}{ Annually Oyster Consumption (times) } \\
\hline 0 & $24.27 \%$ \\
\hline $1-2$ & $35.69 \%$ \\
\hline $3-5$ & $22.82 \%$ \\
\hline $6-9$ & $8.29 \%$ \\
\hline 9 or more & $8.92 \%$ \\
\hline
\end{tabular}

the household's primary shopper, and the average age was 37 . The respondents' political beliefs were diverse and their incomes were representative of a normal distribution. Most (58 percent) participants consumed oysters between one and five times in a year. 
As in all experimental economic studies, sample representativeness was a concern. We tried to sample only individuals who ate or were willing to try oysters, by first asking in the recruitment protocol about whether the person eats oysters. This procedure could have introduced a degree of sample selection bias since all who chose to participate were interested in the product. We acknowledge that these factors restrict the extent to which the findings can be fully generalized to broader populations.

We investigated consumers' valuations of eight oyster attributes: species, shell size, meat size, saltiness, smell, shell color, meat color, and harvest location. Participants rated their valuations of each attribute on a 1-9 scale in which 1 represented not at all important and 9 represented extremely important. As shown in figure 1, on average, participants valued smell the most (average score of 7), followed by saltiness, meat size, and meat color (scores of 6) and then by shell size, shell color, and harvest location (scores of 5). The least valued attribute was oyster species (score of 4). Table 2 presents correlation coefficients for consumer valuations for pairs of attributes. All of the coefficients are significantly correlated at the 1percent level of significance and positive, indicating that consumers who believe that one oyster attribute is very important are likely to place relatively high values on other attributes.

We used a factor analysis to aid in identifying potential influences on consumption behavior such as general perceptions of seafood safety and quality. ${ }^{3}$ As shown in table 3, the factor loadings and selection of scale (Hair

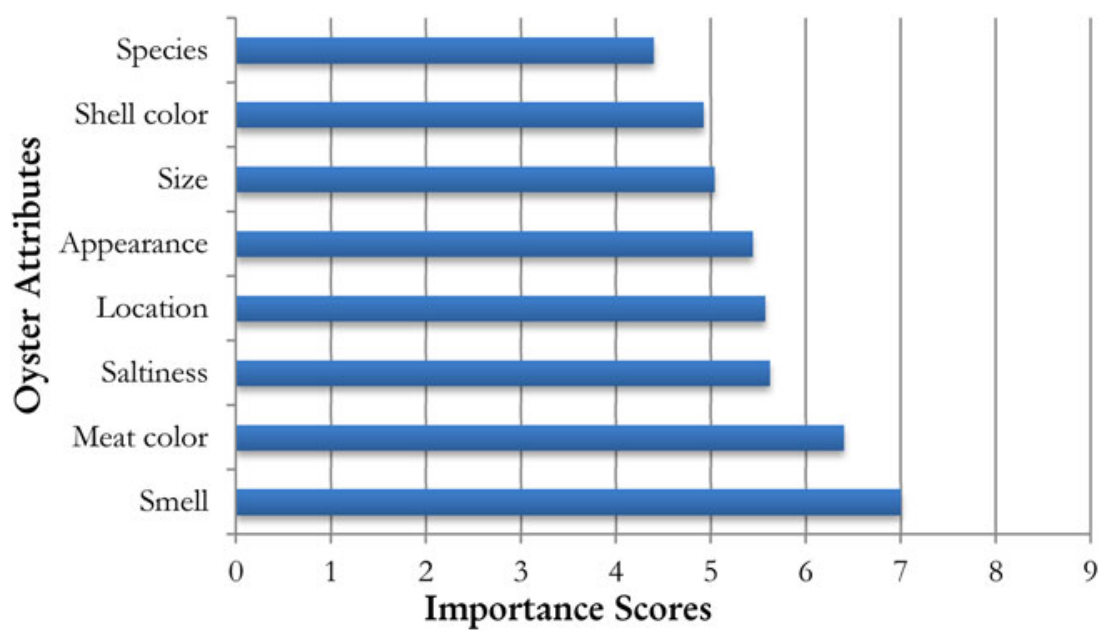

Figure 1. Importance of Oyster Attributes

3 We note that Latent Class Analysis is an alternative to Factor Analysis. The questions included in this research covered all the elements we identified upon working closely with a number of 
Table 2. Correlation Coefficient between Consumer Valuations for Oyster Attributes

\begin{tabular}{|c|c|c|c|c|c|c|c|c|}
\hline & Smell & Meat Color & Saltiness & Location & Appearance & Size & Shell Color & Species \\
\hline Smell & 1.00 & & & & & & & \\
\hline Meat color & 0.57 & 1.00 & & & & & & \\
\hline Saltiness & 0.41 & 0.47 & 1.00 & & & & & \\
\hline Location & 0.27 & 0.43 & 0.27 & 1.00 & & & & \\
\hline Appearance & 0.35 & 0.51 & 0.38 & 0.31 & 1.00 & & & \\
\hline Size & 0.22 & 0.37 & 0.34 & 0.37 & 0.45 & 1.00 & & \\
\hline Shell color & 0.28 & 0.52 & 0.32 & 0.33 & 0.64 & 0.39 & 1.00 & \\
\hline Species & 0.15 & 0.28 & 0.26 & 0.42 & 0.35 & 0.50 & 0.44 & 1.00 \\
\hline
\end{tabular}

Note: The correlation coefficients between all variables are significant at the 1 percent level. 
Table 3. Summary of Factor Analysis Results

\begin{tabular}{lcc}
\hline Variable & Factor Loading & \\
\cline { 2 - 3 } & Factor 1 (Average) & Factor 2 (Advanced) \\
\hline Location & 0.6158 & 0.3379 \\
Species & 0.5855 & 0.3144 \\
Size & 0.6076 & 0.1161 \\
Appearance & 0.6812 & -0.2248 \\
Saltiness & 0.5483 & -0.1506 \\
Smell & 0.5184 & -0.2858 \\
Shell color & 0.6757 & -0.1538 \\
Meat color & 0.7204 & -0.2740 \\
\hline
\end{tabular}

et al., 1998) identified two factors. The first captures a latent sense of perceived importance equally associated with all oyster attributes that we refer to as average. The second describes the latent sense of professional critics regarding oysters as it puts significantly more weight on the harvest location and species. We refer to this factor as advanced. We incorporate these factors in the econometric model and expect that the variable for average will have an insignificant coefficient and the variable for advanced will have a positive coefficient.

In order to identify which consumers are more likely to report high valuations for oyster attributes, we ran an ordinary least square regression with the average importance score for all attributes as the dependent variable and the demographic characteristics as independent variables. The results are summarized in table 4 . In general, people who consumed oysters frequently and primary household shoppers were the most selective as they reported the highest aggregate scores for the importance of oyster attributes. Whether a participant is female, well-educated, or politically liberal did not influence her sense of importance of the attributes. In addition, and age and income had no statistically significant effect.

Next, using a random effects logit model, we investigated factors that influence participants' oyster purchasing decisions (table 5). As expected, price had a significant and large negative effect and income had a significant positive effect. Specifically, when price increased by one dollar, participants are 21 percent less likely to say "yes" to buying oysters. Income has a relatively small effect. When the income increased by one category, the

oyster experts prior to conducting this research. Therefore, we used Factor Analysis because our main objectives are to find the correlation among these elements instead of identifying the underlying, unobserved factors. 
Table 4. Consumers Who Reported Higher Importance Score on Overall Oyster Attributes

\begin{tabular}{lcc}
\hline Parameters & Coefficient Estimates & Standard Error \\
\hline Frequent consumer & $0.26^{* * *}$ & 0.06 \\
Female & -0.20 & 0.13 \\
Liberal & -0.13 & 0.14 \\
Age & -0.00 & 0.00 \\
Education & -0.04 & 0.14 \\
Income & 0.01 & 0.02 \\
Primary shopper & $0.25^{*}$ & 0.14 \\
Constant & 4.86 & 0.28 \\
\hline
\end{tabular}

Note: * represents significance at the 10 percent level, ${ }^{* *}$ at the 5 percent level, and ${ }^{* * *}$ at the 1 percent level.

$\mathrm{N}=471$

Table 5. Coefficient Estimates of the Explanatory Variables on YesDecisions

\begin{tabular}{lcc}
\hline Parameters & Coefficient Estimates & Standard Error \\
\hline Price & $-1.59(-0.21)^{* * *}$ & 0.10 \\
Frequent & $0.20(0.03)^{* *}$ & 0.09 \\
Female & $-0.42(-0.06)^{* *}$ & 0.18 \\
Age & $-0.03(-0.00)^{* * *}$ & 0.01 \\
Education & $0.03(0.00)$ & 0.06 \\
Income & $0.06(0.01)^{* *}$ & 0.03 \\
Primary shopper & $0.32(0.04)^{*}$ & 0.19 \\
Advanced & $0.23(0.03)^{* *}$ & 0.11 \\
Average & $0.02(0.00)$ & 0.11 \\
Low nutrient & $0.21(0.03)$ & 0.14 \\
Moderate nutrient & $0.87(0.11)^{* * *}$ & 0.13 \\
High nutrient & $0.83(0.11)^{* * *}$ & 0.13 \\
\hline
\end{tabular}

Note: ${ }^{*}$ represents significance at the 10 percent level, ${ }^{* *}$ at the 5 percent level, and ${ }^{* * *}$ at the 1 percent level.

Numbers in the parentheses represent the marginal effects of variables.

$\mathrm{N}=3,888$ 
probability of a participant saying "yes" to an option increased by 1 percent. People who knew the nutrient level of the water in which the oysters were produced were more likely to buy. Furthermore, participants were more likely to buy when the oysters came from waters containing a moderate or high level of nutrients. Harvested from either moderate or high nutrient water yielded an 11 percent increase in the probability of a participant saying "yes" to the oyster option. Older participants and those who were relatively selective regarding shell color or smell were less likely to buy oysters while women and advanced consumers were more likely to buy.

In our sample, 58 percent chose fried oysters, 28 percent chose raw on the half shell, and 14 percent chose to take them home. Consequently, we were particularly interested in the characteristics of consumers who preferred fried oysters since that represented the majority of people's. The results of a logit model, which are presented in table 6, suggest that those who consumed oysters most frequently preferred raw. Relatively educated consumers also did not prefer fried oysters. Instead, fried oysters were preferred by women and primary household shoppers. In addition, consumers who valued advanced oyster attributes such as species and harvest location preferred to consume oysters raw. Those who were selective (reported the attributes of the oysters overall as important) preferred fried to raw. The level of nutrients in the water from which the oysters were harvested did not have a significant impact on participants' preferences for preparation method.

Table 6. Consumers Who Are More Likely to Choose Fried Oysters

\begin{tabular}{lcc}
\hline Parameters & Coefficient Estimates & Standard Error \\
\hline Frequent & $-0.45^{* * *}$ & 0.09 \\
Female & $0.49^{* *}$ & 0.21 \\
Age & -0.00 & 0.01 \\
Education & $-0.14^{*}$ & 0.07 \\
Income & 0.04 & 0.04 \\
Primary shopper & 0.26 & 0.22 \\
Advanced & $-0.28^{* *}$ & 0.13 \\
Average & $0.39^{* * *}$ & 0.13 \\
Low & -0.40 & 0.31 \\
Moderate & -0.42 & 0.29 \\
High & -0.33 & 0.30 \\
Constant & $1.82^{* * *}$ & 0.48 \\
\hline
\end{tabular}

Note: * represents significance at the 10 percent level, ${ }^{* *}$ at the 5 percent level, and ${ }^{* * *}$ at the 1 percent level.

$\mathrm{N}=471$ 
Table 7. Marginal Effect of Explanatory Variables on Willingness to Pay

\begin{tabular}{lccr}
\hline Variable & Marginal Effects on WTP & 95\% confident interval & \\
\hline Frequent & $0.13^{* *}$ & 0.01 & 0.24 \\
Female & $-0.27^{* *}$ & -0.49 & -0.04 \\
Age & $-0.02^{* * *}$ & -0.03 & -0.01 \\
Education & 0.02 & -0.06 & 0.10 \\
Income & $0.04^{* *}$ & -0.01 & 0.08 \\
Primary shopper & $0.20^{*}$ & -0.04 & 0.43 \\
Advanced & $0.15^{* *}$ & 0.01 & 0.29 \\
Average & 0.01 & -0.12 & 0.14 \\
Low nutrient & 0.13 & -0.03 & 0.30 \\
Moderate & $0.54^{* * *}$ & 0.37 & 0.71 \\
High & $0.52^{* * *}$ & 0.35 & 0.69 \\
\hline
\end{tabular}

Note: * represents significance at the 10 percent level, ${ }^{* *}$ at the 5 percent level, and ${ }^{* * *}$ at the 1 percent level.

$\mathrm{N}=3,888$

We estimated mean WTP following Hanemann (1984):

$$
W T P=\frac{1}{\hat{\rho}}\left(\hat{\alpha}+\hat{\lambda}^{\prime} \bar{X}\right)
$$

The results suggest that the consumers in our sample were willing to pay an average of $\$ 0.67$ for an oyster. Note that this considers the overall WTP for all participants. Naturally, it includes first-time oyster consumers and people who would be willing to pay for oysters below the market price.

We also calculated the mean and confidence intervals around the estimated marginal WTP for each variable (see table 7) using the delta method (Greene, 2008). We expected nutrient level to have a positive effect on preferences for an oyster, and our results support that hypothesis. The variable representing nutrient level had a statistically significant effect on WTP. Relative to oysters from waters with an unknown level of nutrients, we find premiums of $\$ 0.52$ for oysters from high-nutrient waters and $\$ 0.54$ for oysters from moderatenutrient waters, which are significant at the 1 percent level.

Further extending our analysis, we estimated the marginal effects of the other statistically significant variables on consumer WTP. On average, when an individual's oyster consumption frequency increased by one category, the individual was willing to pay an extra $\$ 0.13$ per oyster. Additionally, the older the consumer, the smaller the WTP. With each additional year in age, the price premium dropped $\$ 0.02$. According to results that were significant at 
the 10 percent level, primary household shoppers were willing to pay $\$ 0.20$ more per oyster and women were willing to pay $\$ 0.27$ less on average. Participants who had higher incomes had greater WTP with the premium increasing by $\$ 0.04$ per oyster in response to a one-category increase in income. In addition, consumers who valued the advanced oyster attributes were willing to pay $\$ 0.15$ more per oyster.

\section{Conclusion}

In addition to serving as a source of food, oysters provide ecosystem services by filtering contaminating nutrients from the surrounding water, and NOAA supports the use of oyster aquaculture as an environmental best management practice. A better understanding of consumers' preferences and purchasing behaviors for oysters is critical for estimating the profitability of the oyster industry and promoting its recovery and sustainability.

This research identifies consumers' preferences, estimates their willingness to pay for various types of oysters, and characterizes their demographic characteristics to provide much needed information for development and expansion of oyster aquaculture in the United States. The potential for oysters to improve water quality is measured by comparing consumers' preferences for oysters from waters with varying degrees of nutrient pollution, and heterogeneity in consumers' preferences is captured through willingness to pay.

We find that the average consumer is willing to pay $\$ 0.67$ for an oyster and that people who consume oysters frequently, households' primary shoppers, and people who have advanced experience with oyster attributes are willing to pay more than women and older consumers. Our results indicate that consumers were more willing to pay for oysters grown in moderate-nutrient and high-nutrient waters than for oysters from low-nutrient waters and waters for which the nutrient level was not known.

In terms of how oysters are prepared, we find that more than half of the consumers in our study preferred fried oysters to fresh oysters on a halfshell. However, fried oysters were not preferred by people who consumed oysters frequently, were relatively highly educated, and who valued advanced oyster attributes. Women and people who generally valued oyster attributes highly preferred fried oysters. The nutrient levels in the water from which the oysters were harvested did not affect consumers' choice of preparation methods.

These findings are useful for policymakers and oyster producers in their efforts to expand and support development of oyster aquaculture programs across the country and for efforts to improve the quality of water through ecosystem services. The industry needs detailed information on consumers' willingness to pay for oysters as producers and others consider investing in large-scale aquaculture operations. 
The results of this study point to several avenues for further research. One is a more detailed analysis of the drivers of consumers' heterogeneous preferences. Why, for example, do women as a group prefer fried oysters to fresh? Potential motives include differences in how the oysters taste and in the relative safety of the preparation methods. Future studies could also seek to identify these motives by including more detailed survey questions, which might include questions concerning participants; preferences for cooked oysters over raw oysters given potential concerns about the safety of raw foods. We also observe heterogeneous willingness to pay for oysters from waters with various levels of nutrient contamination. The underlying reasons for those preferences are still an open question. Another avenue for further research is identification of information treatments that seek to convey the environmental benefits of oyster aquaculture, and seeing whether consumers would pay a price premium for that positive externality.

\section{References}

Anderson, J.L. 1995. "Purchase Behavior, Food Safety, and Quality Control in Seafood and Aquaculture Marketing: Discussion." American Journal of Agricultural Economics 77(5): 1319-1321.

Bricker, S., B. Longstaff, W. Dennison, A. Jones, K. Boicourt, C. Wicks, and J. Woerner. 2007. "Effects of Nutrient Enrichment in the Nation's Estuaries: Decade of Change." NOAA Coastal Ocean Program Decision Analysis Series No. 26. National Centers for Coastal Ocean Science, Silver Spring, MD.

Bruner, D.M., Huth, W.L., McEvoy, D.M., and Morgan, O.A. 2014. "Consumer Valuation of Food Safety: The Case of Postharvest Processed Oysters." Agricultural and Resource Economics Review 43(2): 300-318.

Dedah, C., Keithly Jr, W.R., and Kazmierczak Jr, R.F. 2011. "An Analysis of US Oyster Demand and the Influence of Labeling Requirements." Marine Resource Economics 26(1): 17-33.

Gempesaw, C.M., Bacon, R., Wessells, C.R., and Manalo, A. 1995. "Consumer Perceptions of Aquaculture Products." American Journal of Agricultural Economics 77(5): 1306-1312.

Greene, W.H. 2008. Econometric Analysis ( $6^{\text {th }}$ edition). Pearson Prentice Hall. Upper Saddle River, New Jersey.

Hair, J.H., Anderson, R.E., Tatham, R.L., and Black, W.C. 1998. "Multivariate Data Analysis." New Jersey: Prentice-Hall Inc.

Hanemann, M.W. 1984. "Welfare Evaluation in Contingent Valuation Experiments with Discrete Responses." American Journal of Agricultural Economics 66(3): 332-341.

Kecinski, M., K.D. Messer, L. Knapp, and Y. Shirazi. 2017. "Consumer Preferences for Oyster Attributes: Field Experiments on Brand, Locality, and Growing Method." Agricultural and Resource Economics Review. https://doi.org/10.1017/age.2017.21

Kecinski, M., Messer, K.D., and Peo, A.J. 2016. "Consumer Preferences for the Provision of Water Quality Services by Oysters." APEC working paper (APEC RR16-02). Available at: https://cdn.canr.udel.edu/wp-content/uploads/2016/03/22141033/RR16-02.pdf

Liu, Y., Kow, F., Grewal, D., and FitzGerald, D. 2006. "Consumer Purchase Behavior for Oysters: An Empirical Study in Some State Capital Cities of Australia." International Journal of Consumer Studies 30(1): 85-94.

Loose, S.M., Peschel, A., and Grebitus, C. 2013. "Quantifying Effects of Convenience and Product Packaging on Consumer Preferences and Market Share of Seafood Products: The Case of Oysters." Food Quality and Preference 28(2): 492-504. 
Manalo, A.B., and Gempesaw, C.M. 1997. "Preferences for Oyster Attributes by Consumers in the US Northeast." Journal of Food Distribution Research 28(2): 55-63.

NOAA. 2016a. "Annual Commercial Landing Statistics." Accessed September, 2016 at http:// www.st.nmfs.noaa.gov/st1/commercial/landings/annual_landings.html

— (2016b). "Basic Questions about Aquaculture." Accessed September, 2016 at http:// www.nmfs.noaa.gov/aquaculture/faqs/faq_aq_101.html.

— (2016c). “Oyster Reefs." Accessed September, 2016 at http://chesapeakebay.noaa.gov/ oysters/oyster-reefs.

Rose, J.M., Bricker, S.B., and Ferreira, J.G. 2015. "Comparative Analysis of Modeled Nitrogen Removal by Shellfish Farms.” Marine pollution bulletin 91(1): 185-190.

Venkatachalam, L. 2004. "The Contingent Valuation Method: A Review," Environmental Impact Assessment Review 24(1): 89-124.

Wu, S., Fooks, J., Messer, K.D., and Delany, D. 2014. "Do Auctions Underestimate Consumer WTP? An Artefactual Field Experiment." Department of Applied Economics \& Statistics Working Paper 2014-05.

\section{Appendix A - Experiment Design Roadmap}

Step 1. Experimental questions design. This step included stakeholder input, such as industry experts, restaurant owners and policymakers.

Step 2. Location scouting: This step also included recommendations from stakeholders. We also arranged for professional oyster shucking services, which accompanied us to each experiment. Locations included: Department of Motor Vehicles (DMV), 16 Mile Brewery, Famous Joes Tavern, AG Day 2016.

Step 3. Design Implementation using dichotomous choice experiments. 486 Participants responded either yes or no to 8 dichotomous choice questions.

a. Participants were set up with $\$ 10$.

b. Participants preselected the number of oysters they would want to purchase $(3,6,9$ or 12$)$ and how they would like the oysters prepared (raw, fried or in a bag of ice for take-home).

c. Participants made 8 dichotomous choice decisions.

d. Participants filled out a survey (Appendix B)

e. Random selection of one of the participant's decision - a roll of the dice determined which one of the eight decisions would be implemented (ensured incentive compatibility).

f. If random draw selected a yes decision, the participants paid for the oysters and would receive the oysters as indicated in their preselection (b); if the random draw resulted in a no decision, the participant would receive the $\$ 10$ and no oysters.

Step 4. Data analysis and preparation of manuscript, outreach activities.

\section{Appendix B - Survey}

1. Are you a first time oyster consumer? 

O Yes
O No

2. How often do you consume oysters?

O 0 times per year

○ 1-2 times per year

O 3-5 times per year

O 6-9 times per year

$\bigcirc>9$ times per year

3. Are you the primary shopper in your household?

O Yes

O No

4. In a typical month, approximately how many times do you eat seafood?

5. In a typical month, approximately how many times do you eat at restaurants?

6. When you eat at a restaurant, what is the percentage of seafood versus other food?

7. How often do you eat seafood at home versus at a restaurant?

8. Are you the primary seafood shopper in your household?

O Yes

O No

9. How often do you catch your own seafood?

Never (1) - Very Often (9)

10. How important is location in your oyster choice?

Not Important (1) - Very Important (9)

11. For oysters from the Delaware Bay, I would...

$\bigcirc$ pay more than other locations.

$\bigcirc$ pay less than other locations.

$\bigcirc$ pay the same as other locations.

12. For oysters from the Delaware Inland Bays, I would...

$\bigcirc$ pay more than other locations.

$\bigcirc$ pay less than other locations. 
pay the same as other locations.

13. How do you usually prefer the preparation of your oysters?

O Raw on the half shell

O Raw in a shooter

O Fried

$\bigcirc$ Grilled

Other

14. How important are the following oyster characteristics to you? Oyster Species:

Not Important (1) - Very Important (9)

Size of the oyster shell:

Not Important (1) - Very Important (9)

Size of the oyster meat:

Not Important (1) - Very Important (9)

Appearance of the oyster shell:

Not Important (1) - Very Important (9)

Saltiness of the oyster:

Not Important (1) - Very Important (9)

Smell of the oyster:

Not Important (1) - Very Important (9)

Color of the oyster shell:

Not Important (1) - Very Important (9)

Color of the oyster meat:

Not Important (1) - Very Important (9)

Location of harvest:

Not Important (1) - Very Important (9)

15. On average, how often do you go to the beach each year?

O 0 times per year

○ 1-2 times per year 

3-5 times per year
6 6-9 times per year
$\bigcirc>9$ times per year

16. What is your age?

17. What gender do you identify yourself as?
$\bigcirc$ Male
$\bigcirc$ Female

18. What is your profession?
$\bigcirc$ Government
$\bigcirc$ Academia
Business
$\bigcirc$ Agriculture
Other (please specify)

19. Are you:
$\bigcirc$ Politically liberal
$\bigcirc$ Politically moderate
$\bigcirc$ Politically conservative
Other (please specify)

20 . Which category best describes your household income (before taxes) in 2014?
$\bigcirc$ Less than $\$ 10,000$
○ $\$ 10,000-\$ 14,999$
○ $\$ 15,000-\$ 24,999$
○ \$25,000-\$34,999
○ \$35,000-\$49,999
○ \$50,000-\$74,999
○ \$75,000-\$99,999
○ $\$ 100,000-\$ 149,999$ 

○ $\$ 150,000-\$ 199,999$
○ $\$ 200,000-\$ 249,999$
$\bigcirc \$ 250,000$ and above

21. What is the highest level of education that you have completed? Grade school

O Some high school

High school graduate

O Some college credit

$\bigcirc$ Associate degree

Bachelor's degree

Graduate degree/Professional 